\title{
O PLANEJAMENTO ESTRATÉGICO COMO FERRAMENTA PARA A RENOVAÇÃO DO PENSAMENTO ESTRATÉGICO EM UMA ORGANIZAÇÃO DO TERCEIRO SETOR: O CASO DA OMEP/SM
}

\author{
Profa. Ms. Lucia Rejane da Rosa Gama Madruga' \\ Jonas Cardona Venturini ${ }^{2}$ \\ Bruno Weiblen ${ }^{3}$ \\ Rodrigo de Barros Severo 4
}

\section{RESUMO}

A vidas das organizações tem se modificado nos últimos anos. Até mesmo as organizações orientadas por valores, como é o caso das ONGs, estão buscando respostas mais adequadas para os novos e crescentes desafios que precisam administrar. As ferramentas da administração, onde se destaca o Planejamento Estratégico (PE), estão cada vez a serviço de todos os tipos de organização. Buscar a melhor forma de adaptá-las aos diferentes contextos tem sido uma grande tarefa daqueles que estudam e praticam a administração. Assim, este estudo pretende dar a sua contribuição para a descoberta de mais e melhores alternativas de aplicação dos conhecimentos e teorias administrativas. Para tal, buscou a aplicação da ferramenta de PE em uma ONG da área educacional, com a finalidade de buscar a sua consciência estratégica e a conseqüente mudança em seu pensamento estratégico. Com o desenvolvimento do estudo foi possível evidenciar, através de um processo de pesquisa-ação, os traços culturais da organização e a contribuição do planejamento tanto para a sua aprendizagem administrativa quanto para o reposicionamento de suas estratégias, colocando-a em um patamar gerencial mais adequado às exigências contextuais.

Palavras-chave: Terceiro Setor, Planejamento Estratégico.

\footnotetext{
${ }^{1}$ Profá. Ms. do Departamento de Administração da Universidade Federal de Santa Maria

${ }^{2}$ Acadêmico de Ciências Contábeis e Administração da UFSM

${ }^{3}$ Acadêmico de Administração da UFSM

${ }^{4}$ Acadêmico de Administração da UFSM
} 


\section{INTRODUÇÃO}

As mudanças no contexto gerencial afetaram também as organizações do terceiro setor. Esta constatação evidenciou a necessidade de um agir profissionalizado em todos os processos que envolvem a árdua tarefa de gerenciar uma organização dessa natureza.

Esse processo levou a OMEP buscar o apoio técnico-administrativo necessário para aproximar o seu sistema de gestão aos modelos gerenciais contemporâneos que, sabidamente levam à ação reflexiva que traz consigo a mudança de postura almejada.

Assim, através de um projeto que congregou as atividades de ensino, pesquisa e extensão, desenvolveu-se o estudo que originou este artigo. $O$ primeiro passo consistiu no diagnóstico da organização que evidenciou as ações a serem desenvolvidas prioritariamente. Nesse momento foi identificada a necessidade primordial de redefinição estratégica da organização, o que foi buscado a partir da reorientação de seu pensamento estratégico. O problema investigado centrou-se na inserção do Planejamento Estratégico (PE), como ferramenta para a renovação do pensamento estratégico em uma organização do terceiro setor, vocacionada para o atendimento das necessidades da criança enquanto cidadã, sujeito de direito. Tratase, portanto, de um estudo de caso, apoiado na metodologia da pesquisa-ação.

Os objetivos do trabalho consistem em discutir o processo de PE desenvolvido na Instituição e sua influência no pensamento estratégico organizacional, assim como evidenciar os traços culturais da organização que demandaram uma aplicação muito peculiar dessa ferramenta.

\subsection{A INSTITUIÇÃO}

A OMEP é uma entidade não governamental, de defesa dos direitos da criança, com prioridade para a primeira infância, caracterizando-se como uma Organização sem fins lucrativos, com metas diretrizes e princípios filosóficos e políticos próprios e participativamente definidos no sentido de por eles orientar suas ações. Os grandes desafios desta Instituição estão voltados para o desenvolvimento de ações capazes de efetivamente contribuir para que se cumpram os direitos fundamentais das crianças. Defende que uma Política Social para a Infância deve estar baseada em uma proposta crítica e criativa de transformação social, voltada para a criança como sujeito de direitos plenos, ativo, histórico, construtor de suas relações com o mundo e com a sociedade na qual se insere. Os princípios que fundamentam a sua atuação 
são a democracia, a diminuição das desigualdades sociais e autopromoção da criança enquanto sujeito e cidadã.

\section{RESPONSABILIDADE SOCIAL}

O crescente aumento da complexidade dos negócios e as demandas sociais cada vez mais desiguais têm feito com que as organizações repensem a forma como estão se relacionando com seus diversos públicos, onde se inclui a própria sociedade. Assim, as organizações têm visto na responsabilidade social uma nova estratégia para potencializar tanto o seu desenvolvimento como proporcionar á sociedade alternativas em busca de um desenvolvimento sustentável.

Ferrell et al (2001) define a responsabilidade social no mundo dos negócios como a obrigação da empresa de maximizar seu impacto positivo sobre os stakeholders (clientes, proprietários, empregadores, comunidade, fornecedores e governo) e em minimizar o negativo.

Ashley et al afirma que "responsabilidade social pode ser definida como o compromisso que uma organização deve ter para com a sociedade, expresso por meio de atos e atitudes que afetem positivamente, de modo amplo, ou a alguma comunidade, de modo específico, agindo proativamente e coerentemente no que tange a seu papel específico na sociedade e a sua prestação de contas para com ela". (2002, p.6)

Os conceitos anteriores enfatizam que a empresa socialmente responsável é aquela que amplia as suas ações, incluindo como parte de seu planejamento os reflexos e impactos no contexto social. Neste sentido, Jaramillo e Ángel apud Ashley et al (2002, p.7) afirmam que "Responsabilidade social pode ser também o compromisso que a empresa tem com o desenvolvimento, bem-estar e melhoramento da qualidade de vida dos empregados, suas famílias e comunidade e em geral".

A responsabilidade social ainda é um conceito em construção, pois tanto no nível acadêmico como no prático as interpretações acerca da mesma são divergentes. Contribuindo com esse debate, destaca-se o pensamento de Votaw apud Ashley et al (2002, p.7) ao afirmar que:

Responsabilidade social significa algo, mas nem sempre a mesmas coisa, para todos. Para alguns, ela representa a idéia de responsabilidade ou obrigação legal; para outros, significa um comportamento responsável no sentido ético; para outros, ainda, o significado transmitido é de responsável por, num modo casual. Muitos simplesmente equiparam-na a uma 
contribuição caridosa; outros tomam-na pelo sentido de socialmente consciente.

A figura 1, destaca os vetores da responsabilidade social:

\section{Satisfação de clientes e consumidores}
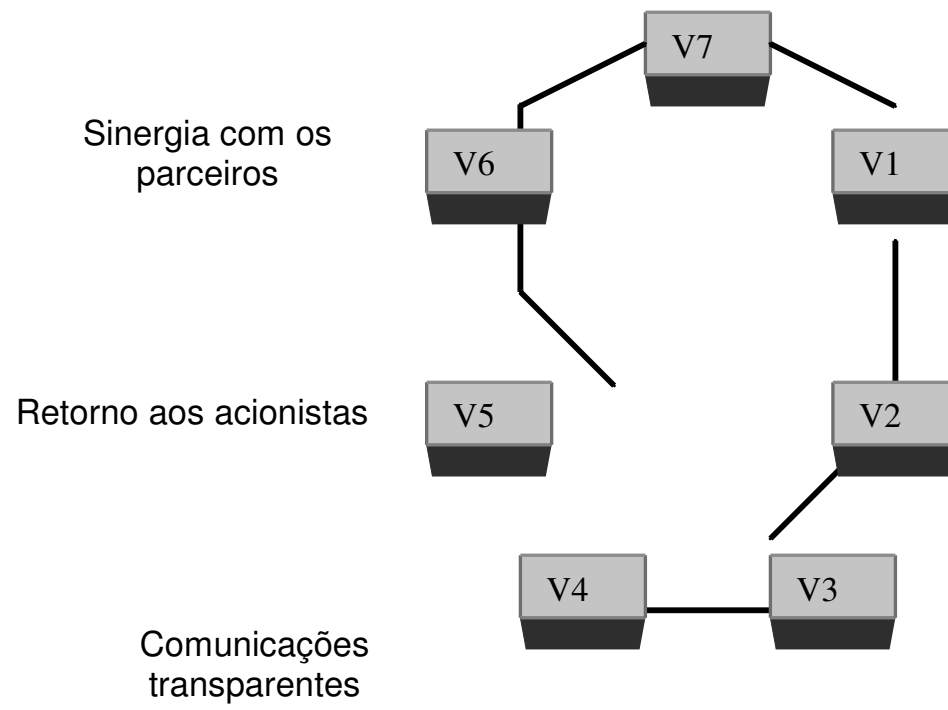

Apoio ao desenvolvimento da comunidade na qual atua transparentes funcionários e dependentes e em um ambiente de trabalho agradável

Fonte: Ashley et al (2002).

Figura 1: Vetores da responsabilidade social

Complementando as definições apresentadas para a responsabilidade social, acrescenta-se a visão de Ferrell et al (2001), que coloca a responsabilidade social em quatro patamares: Filantrópico: "restituir" à sociedade o que dela foi recebido; Econômico: maximizar para o stakeholder a riqueza e o valor; Ético: seguir padrões de conduta aceitável, da maneira definida pelos stakeholders e Legal: cumprir todas as leis e regulamentos do governo.

Melo Neto e Froes (2001), classificam a responsabilidade social como uma ação estratégica da empresa que busca retorno econômico, social, institucional e tributário-fiscal, que é coletiva mobilizadora e inclusiva. 


\section{ORGANIZAÇÕES DO TERCEIRO SETOR}

De acordo com Levitt (1973), o surgimento das organizações do terceiro setor aconteceu na Inglaterra, em 1601, onde a Rainha Elizabeth I instituiu uma legislação para organizar o combate à pobreza, que era feito com recursos obtidos dos impostos pagos pelos Estados. Esse documento, o "Estatuto dos Usos Caritativos", foi implantado na Velha Inglaterra e teve grande influência na Nova Inglaterra, parte do que iria formar, mais tarde os Estados Unidos da América. A carência de recursos e instituições formais sentida pelos novos imigrantes, além de pouca confiança em governos, ajudaram a criar nos EUA um setor filantrópico.

A segunda metade do século XX viu expandir e disseminar-se por todos os pontos do globo que Salamon (1996) chama de nova onda associativa: criação de centenas de milhares de organizações, fora do âmbito do governo ou do setor privado, cujo objetivo é trabalhar em benefício público. No Brasil, por sua constituição ter se dado a partir de colonizadores que tinham o intuito prioritário de exploração de recursos naturais, em prol da metrópole (Portugal), não se desenvolveu um espírito de desenvolvimento comunitário. Além disso, as relações históricas entre Estado e sociedade civil no Brasil reforçaram posicionamentos de não participação comunitária. Desde a colonização existiram as associações formadas a partir de valores católicos - caridade e filantropia - que prestavam serviços sociais, assistenciais e de saúde (são exemplos as Santa Casas). Estas associações, que tinham o intuito de ajudar os pobres e incapacitados, eram formadas a partir do sentimento de dever dos católicos, que creditavam à caridade e ao cumprimento de suas obrigações a salvação e/ou o perdão divino.

Nos anos 80, as ONGs tiveram uma significativa participação nos processos de democratização política, passando, á defesa de reivindicações que extrapolaram a disputa entre as classes, constituídas nos grupos ou identidades específicas: o negro, o índio, a mulher, homossexuais, sem-terra. Neste momento o termo "sociedade Civil" ganha corpo, pois incentivava a prática da cidadania (o ato de votar) e repassava a noção, ainda que primária, de responsabilidade para com a "coisa pública" e de participação nos rumos da sociedade. Kisil (1997) enfatiza que foi assim que surgiram as organizações privadas de defesa do interesse público no país e o nosso tradicional assistencialismo começou a dar lugar a esse sistema bem mais dinâmico e diversificado que temos hoje e que estamos chamando de terceiro setor.

A idéia de um terceiro setor pressupõe um primeiro e um segundo. Nesse sentido, Kisil (1997) afirma que o primeiro setor é o governo, que utiliza seu papel regulador pelo cumprimento das decisões legais, além de estabelecer políticas públicas. Já o segundo setor seria o mercado, cujo interesse é regulado pelos indivíduos que dele fazem parte, sem qualquer referência a bens públicos. 
Produzem mercadorias e serviços, gerando bens, produção e renda. É interessante notar que o desenvolvimento da comunidade pode tornar-se um assunto que obrigue os três setores a trabalharem juntos para o benefício social.

$O$ autor continua, enfatizando que o terceiro setor refere-se a um conjunto de iniciativas privadas com fins públicos, e cuja confiança estaria nos mecanismos voluntários, na solidariedade humana, apelando para o senso de interesse público. Assim sendo, as organizações do terceiro setor possuem duas características principais: não atribuem lucros a seus fundadores, diferente do setor privado, nem estão a controle político partidário direto.

Conjugados, o terceiro setor - o universo das organizações sem fins lucrativos, ONGs, fundações, institutos - e as empresas socialmente responsáveis estão fazendo a diferença em milhares de cidades, comunidades e escolas. Estão também mudando o perfil do nosso mundo, e chamando a todos para compreender e aprender seus ensinamentos, que vêm provando ser um caminho para o desenvolvimento cooperativo, responsável e sustentável. As empresas e as organizações do terceiro setor passaram a construir parcerias e alianças estratégicas, buscando soluções para problemas sociais que afligem o mundo e objetivando oportunizar o enfrentamento das desigualdades. 


\section{O PLANEJAMENTO ESTRATÉGico E SUA RELAÇAO COM O PENSAMENTO ESTRATÉGICO EM ORGANIZAÇÕES DO TERCEIRO SETOR}

O PE tem se destacado pela ação reflexiva que desencadeia nas organizações. Independentemente da área de atuação dessas organizações a ferramenta de planejamento contribui para o estabelecimento de uma nova filosofia organizacional oriunda desse processo reflexivo que possibilita a visualização de um futuro mais focado em ações orientadas pelas demandas do contexto interno e externo.

O pensamento estratégico da organização é um fator fundamental para o estabelecimento de diretrizes organizacionais orientadoras de seus processos, que se originam da criação de uma competência organizacional voltada para a sua capacidade intelectual, onde os cérebros de seus integrantes são colocados a pensar sobre o futuro das organizações, fazendo conjecturas e simulações sobre as diversas possibilidades elencadas para ao enfrentamento dos desafios organizacionais. Neste sentido Amoroso apud Almeida e Costa (2002, p. 48) enfatiza que "Nossa capacidade de lidar com o pensamento estratégico esta de alguma forma associada com nossa habilidade de utilizar a mente, desenvolver a plasticidade e a capacidade do cérebro, realizar interconexões complexas (sinapses) e de estarmos conscientes desse processo e das conseqüências do que pensamos e de como agimos".

O autor define esse processo como "consciência estratégica" que consiste em desenvolver a capacidade de lidar com o pensamento estratégico e transformá-lo em ação estratégica. O estudo desenvolvido na organização em questão centrou-se nesse contexto e buscou fazer com que a organização desenvolvesse a consciência estratégica. Para tanto, lançou mão do PE, como ferramenta de intervenção e mudança organizacional.

Em organizações orientadas por valores é muito comum existirem pessoas que se identificam com seus valores, mas procuram conduzir as ações organizacionais de acordo com aquilo que para elas e o mais importante. A tarefa do processo de planejamento, passa a ser, portanto, buscar a visualização de um horizonte comum a todos os apoiadores da instituição, que possa gerar um esforço coletivo e sinérgico das pessoas em prol dos objetivos organizacionais. Hudson (1999, p.69) destaca que para organizações dessa natureza "a estratégia é 
particularmente importante por que existem sempre coalizões de pessoas com aspirações diferentes que precisam ser integradas para que a organização progrida".

O mesmo autor afirma que uma filosofia para administrar estratégias em organizações orientadas por valores pode ser derivada de três conceitos: missão, objetivos e estratégia e implica no desenvolvimento dentro da organização de uma clara visão sobre essas questões que possa minimizar o efeito das constantes mudanças internas ou externas que afetam o desempenho dessas organizações. Um dos aspectos importantes é a mobilidade das pessoas que fazem parte desse tipo de atividade, as quais podem estar ali para cumprir a sua missão de vida e não necessariamente a missão da própria organização.

Diante disso, verifica-se que a administração estratégica torna-se uma importante ferramenta porque cria "uma conexão intelectual" entre as pessoas ao mesmo tempo em que permite a formação de coalizões em torno de novas prioridades consensadas no processo de planejamento. Certamente aos constatar que as organizações orientadas por valores carecem de uma orientação estratégica que possa sustenta-las diante de tantas transformações no ambiente econômico, organizacional e social que as circunda, surge um questionamento crucial: por onde começar?

É justamente nesse momento que o PE surge como um ferramental de apoio, por se tratar de uma seqüência de reflexões que pode conectar a organização com o seu ambiente interno e externo, permitindo o estabelecimento de estratégias que a coloquem em posição de competitividade.

\section{METODOLOGIA}

Este capítulo foi reservado para a apresentação da metodologia que orientou o estudo de caso, bem como a metodologia de planejamento utilizada.

\subsection{Metodologia de pesquisa}

O Método da Pesquisa-ação mostrou-se adequado para o desenvolvimento do estudo proposto, pois, conforme Thiollent, um dos principais objetivos dessa metodologia é "dar aos pesquisadores e grupos participantes os meios de se tornarem capazes de responder com maior eficiência aos problemas da situação em que vivem, em particular sob forma de diretrizes de ação transformadora". (1985, p. 
8). Moscovici (1999) salienta que este modelo possui um esquema conceitual de abordagem da situação e um conjunto de atividades para a resolução dos problemas detectados que o torna útil nos programas de mudanças que envolvem uma dimensão psicossocial. Cohen e Fink (2003, p. 360) afirmam que "as atividades experimentais e de diagnóstico necessárias sugerem que o método de pesquisaação é o mais adequado para um esforço planejado de mudanças". Os passos foram adaptados de Thiollent (1985), Moscovici (1999) e Cohen e Fink (2003) e correspondem à definição do problema, coleta de dados, diagnóstico, ação e avaliação.

A definição do problema concentrou-se na percepção do problema e na sua formulação para definir a espécie e relevância dos dados a serem levantados para sua solução. De acordo com Thiollent (1985) este momento inclui uma "perspectiva de aprendizagem de participação" que implica em uma colaboração ativa entre os saberes do pesquisador e dos pesquisados. A coleta correspondeu à definição das técnicas e instrumentos adequados para obter e organizar os dados. Observação participante, entrevistas individuais ou coletivas, questionários, roteiros e reuniões, técnicas documentais, são exemplos de atividades de informações que foram utilizadas.

A fase de diagnóstico foi o momento de confrontar o estado atual com o estado desejado a fim de estabelecer um panorama de possibilidades para encurtar a distância entre esses dois estados e escolher a solução mais adequada. A ação envolveu o desenvolvimento do planejamento estratégico e correspondeu a um momento de aprendizagem conjunta, decorrente das ações de educar, comunicar e organizar, próprias do processo de pesquisa. Conforme proposto por Thiollent (1985) o seminário foi utilizado como instrumento de comunicação, aprendizagem, socialização e transparência do processo de pesquisa. Por fim, a avaliação consistiu em mensurar os resultados para verificar a eficiência e eficácia da intervenção. Os resultados conduziram a um novo ciclo de pesquisa-ação focado na implementação do planejamento estratégico, caracterizando o processo dinâmico da pesquisa.

Cabe destacar nesse método a importância do contexto teórico, especialmente neste caso, onde a geração de idéias, diretrizes e interpretações proporcionadas pela teoria é fundamental. Thiollent (1985) afirma que o fato da pesquisa-ação ter uma vocação de pesquisa prática não elimina a necessidade de articular os projetos dentro de um quadro de referência teórico adaptado ao contexto 
social analisado. Quanto a esse aspecto destaca-se o desenvolvimento e adequação das orientações acerca do planejamento propostas pelos autores que subsidiaram o modelo aplicado. Salienta-se as contribuições de Oliveira (1999) e Vasconcellos e Pagnoncelli (2001).

\subsection{Metodologia de Planejamento Estratégico na OMEP}

O modelo de planejamento utilizado procurou ser o mais simplificado possível, dadas as peculiaridades do público em questão, o qual era constituído de pessoas com formação predominantemente pedagógica que se ligam à organização através de trabalho voluntário.

A primeira etapa consistiu em um Seminário sobre a Metodologia de Planejamento Estratégico que colocou os integrantes da organização a par dessa ferramenta. A metodologia sensibilizou a Diretoria que optou por desenvolver o processo com a participação de todos os seus membros e representantes do grupo de associados.

A elaboração do PE se iniciou com a definição da "visão de futuro", a qual sintetizou os conceitos de visão, missão e valores. Após desenvolveu-se a análise do ambiente, a definição dos objetivos, estratégias e ações e o plano de ação. Todas essas etapas foram realizadas através de reuniões, observação participante e seminários. Por fim, foi realizado um seminário com a Diretoria e associados para divulgar e difundir o planejamento, a fim de buscar o efetivo comprometimento das pessoas com a sua implementação.

\section{RESULTADOS}

O PE levou ao processamento analítico e sistemático da estratégia que existia na mente dos participantes, reposicionando a organização no seu segmento de atuação. O processo combinou dois sistemas complementares, apresentados por Ansoff (1984): os sistemas de posicionamento (introduzidos pelo próprio planejamento) e os sistemas em tempo real (que estavam atrelados à cultura organizacional). Tais sistemas são indicados pelo autor para lidar com estratégias em contextos de incertezas e turbulências. 


\subsection{Traços culturais da Instituição evidenciados no processo de planejamento}

Durante o desenvolvimento do trabalho foi possível evidenciar alguns traços culturais marcantes da Instituição que impactam o seu funcionamento e influenciaram o processo de planejamento desenvolvido. Dentre esses traços, o mais marcante refere-se ao trabalho voluntário. Todos os dirigentes e pessoas chaves para a organização são voluntários e dedicam uma parcela significativa de seu tempo pessoal para apoiar as diversas atividades por ela desenvolvidas. Essa característica tem seus pontos fortes, mas também representa uma grande dificuldade gerencial uma vez que todo o trabalho voluntário dessas pessoas é também controlado e coordenado por outros voluntários. Esse processo implica em dificuldades gerenciais, administrativas e operacionais, pois em diversas situações essas pessoas priorizam outras necessidades pessoais e profissionais em detrimento do trabalho voluntário que realizam, o que não é nenhum demérito, por que certamente elas precisam sobreviver e/ou manter um espaço profissional ou pessoal já conquistado.

Outro traço marcante é o fato dessa organização ser gerenciada por pessoas da área da educação que não dominam as técnicas gerenciais e têm sua experiência administrativa em organizações do meio educacional. Em geral, os dirigentes possuem formação em gestão de escola, o que é um trabalho diferenciado da gestão de uma ONG. Também é importante evidenciar que seu quadro diretivo é composto, em sua maioria, por professoras aposentadas que dividem o seu tempo entre a ação voluntária e a vida pessoal já consolidada com outros objetivos que muitas vezes conflitam com o trabalho voluntário. Além disso, muitas delas, apesar de aposentadas, trabalham em escolas, universidades ou faculdades locais.

\subsection{Visão de futuro}

A Visão de Futuro da organização centrou-se nos direitos da criança e orientou um posicionamento estratégico diferenciado daquele que vinha orientando as ações da organização. A figura 2, ilustra a "Visão de Futuro" definida para a organização:

* Nosso compromisso é com a defesa do direito à educação da criança.

* Buscamos ser reconhecidos como uma ONG de vanguarda em ações relativas à infância.

* Nossos valores são:

- CIDADANIA- de toda criança, sujeito de direito;

- DEFESA - do direito à educação de qualidade de toda criança;

- QUALIDADE - dos serviços oferecidos, primando pela objetividade e adequação à realidade;

- RESPEITO - às diferencas. defendendo a crianca de todas as formas de violacão dos 


\subsection{Análise ambiental}

Os resultados da análise ambiental indicaram que a organização estava muito mais voltada para o seu contexto interno em detrimento do contexto externo e levou à constatação de que não estava aproveitando adequadamente grande parte das oportunidades que lhe eram apresentadas.

As oportunidades e ameaças mapeadas estão evidenciadas na figura 3:

\begin{tabular}{||l||}
\hline \multicolumn{1}{|c|}{ Oportunidades } \\
- \\
Apoio do governo à criança de o a 3 anos; \\
reconhecidas; \\
- Crianças com direitos violados que necessitam \\
atendimento social, O núcleo familiar, não \\
somente com a gestão da criança em situação de \\
risco; \\
- Responsabilidade social; \\
- Demanda por qualificação técnica para \\
profissionais que atuam com crianças (de órgãos \\
governamentais ou não); \\
- Número significativo de crianças, Famílias e suas \\
... _ _ -
\end{tabular}

\begin{tabular}{l}
\hline \multicolumn{1}{|c||}{ Ameaças } \\
- Nova LDB; \\
- Cursos oferecidos por outras instituições; \\
- Concorrência externa por outras \\
instituições; \\
- Situação econômica do país em geral; \\
- Instituições com pouca seriedade \\
atuando na mesma área; \\
- Não financiamento para educacão \\
\hline \hline
\end{tabular}

Figura 3: Oportunidades e ameaças

A análise interna levou à constatação de que o principal foco de atuação deveria ser a autosustentação financeira da instituição. 


\section{Forças}

- Diretoria constituída por pessoas que representam outras instituições

- Reconhecimento regional da organização

- Cursos e estrutura

- Reconhecimento da comunidade

- Imagem (marca)

- Referência para cursos

- Credibilidade e reconhecimento pelas pessoas que a compõem, Resultado dos trabalhos

- Participação em conselhos municipais

- Registro no Conselho Nacional de Assistência Social e no Conselho Municipal de Assistência Social

- Eventos de Educação, Envolvimento das pessoas com a proposta da organização

- Arquivo, Biblioteca

- Reconhecimento no meio OMEP - Brasil

- Abertura de cursos no campo de aprendizagem para alunos e professores, Apoio e parcerias de voluntários e instituições

\section{Fraquezas}

- Falta de autosustentação financeira

- Trabalho voluntário (sistematização por pessoas voluntárias)

- Limitação do atendimento ao público

- Excesso de atribuições sobre a Presidência

- Inadimplência

- Dificuldade de coordenação do trabalho voluntário

- Falta de pessoas remuneradas nos postos chaves

- Biblioteca - atualização

- Arquivo - manutenção

- Estatuto

- Estrutura organizacional

- Horários (conciliar)

- Dificuldade de manutenção

- Falta de um corpo docente comprometido

Figura 4: Forças e fraquezas

\subsection{Objetivos, estratégias e ações}

Anteriormente as estratégias da organização estavam direcionadas de forma indireta para a criança. Todas as suas ações procuravam atingir públicos que atuassem com a criança, mas não a criança diretamente, a exemplo disso destacam-se os cursos de formação e atualização de professores, participação em conselhos atrelados a criança, dentre outros.

A reflexão proporcionada pelo planejamento levou a uma redefinição de seu foco estratégico passando a sua estratégia e ações a atingir diretamente a criança, como forma de atender mais intensamente a sua missão de respaldar e proteger a criança no âmbito social, educacional e pedagógico.

Alem disso, a organização posicionou fortemente a sua estratégia na busca de autosustentação, no incremento das ações sociais voltadas a criança e na qualificação de suas ações pedagógicas. A figura 5 apresenta os objetivos, as estratégias e as ações. 


\section{Ampliar a busca da autosustentação financeira da OMEP até dez 2004}

1.1 Desenvolver accões relativas aos associados

1.1.1 Ampliar o número de associados

1.1.2 Ampliar a oferta de benefícios e serviços aos associados

1.1.3 Fidelizar os atuais clientes

1.2 Desenvolver ações relativas às crianças

1.2.1 Desenvolver atividades lúdicas de férias

\section{Incrementar as ações sociais da OMEP até dez 2004}

2.1 Intensificar o apoio pedagógico ao Lar Vila das Flores

2.1.1 Buscar parcerias e/ou convênios efetivos para o espaço lúdico pedagógico do Lar Vila das Flores

2.2 Intensificar apoio à ludoteca comunitária

2.2.1 Criar recantos de ludicidade

2.2.2 Intensificar projetos

2.2.3 Aperfeiçoar o grupo da ludoteca e intercambiar experiências

\section{Qualificar as ações pedagógicas da OMEP até dez 2004}

3.1Redefinir o Núcleo de Estudos sobre educação infantil

3.1.1 Dar continuidade ao processo avaliativo do trabalho do Núcleo e redimensioná-lo

3.2 Fomentar os eventos fortalecedores da Imagem Institucional

3.2.1 Diversificar o público-alvo dos eventos

3.2.2 Realizar Jornadas Estaduais de Educação Infantil

Figura 5: Objetivos, estratégias e ações

Ao finalizar esse capítulo cabe enfatizar o papel do PE na redefinição estratégica da organização e a constatação de que, através dessa importante ferramenta gerencial, é possível interferir na administração de uma organização dessa natureza produzindo efeitos satisfatórios no que diz respeito ao seu gerenciamento mais eficiente e eficaz, o que tem reflexos não só nesses aspectos, mas principalmente, na criação de melhores condições para que possam concretizar a sua importante missão na sociedade.

\section{CONCLUSÃo}

O desenvolvimento desse estudo possibilitou, não somente a aplicação e avaliação prática de uma metodologia, mas um processo de aprendizagem tanto por parte dos pesquisadores quanto da organização pesquisada. Isto pode ser constatado pelo depoimento da sua Diretoria executiva:

"Acredita-se que todos crescemos. Os professores, pela possibilidade de relacionar teoria prática diante dos seus estagiários. Os estagiários pelo contato com a realidade, os quais, na observação silenciosa, em determinados momentos 
do debate, certamente, constataram a distância entre a prática ideal e a possível".

"A equipe OMEPIANA, não só pela aprendizagem de novos conceitos em termos de planejamento, mas pela vivência de uma parceria que abriu possibilidades para a entidade planejar e executar as grandes linhas de trabalho para os próximos anos".

Como resultados práticos sobre a metodologia de PE foi possível evidenciar a sua contribuição para o reposicionamento estratégico da instituição, observado na mudança de seu pensamento estratégico que focava indiretamente a criança, estava voltado para o ambiente externo e baseava-se majoritariamente num sistema em tempo real, o qual passou a focar estrategicamente a criança, voltar-se também para o ambiente externo e basear-se num sistema de posicionamento aliado ao sistema em tempo real, já praticado.

O processo acarretou melhores condições de administrar estrategicamente a organização contribuindo para a sua grande missão de "defesa do direito à educação da criança", e reforçando os valores de "cidadania, defesa, qualidade e respeito". O depoimento da Diretoria reforça essa contribuição ao afirma que: "Realizou-se então uma série de reuniões ao longo de 2002 e 2003, analisando-se as oportunidades e ameaças do ambiente externo e os pontos fortes e fracos da Organização. Estabeleceram-se os objetivos, estratégias e ações que pudessem fazer cumprir a MISSÃO da OMEP".

Por fim, fica evidente que nas organizações orientadas por valores, unir suas crenças com sua estratégia, é uma alternativa de diferenciação e conquista de melhores condições gerenciais para fazer frente ao ambiente competitivo e incerto que não exclui nem mesmo organizações tão motivadas pelo profundo desejo de ajudar a mudar a sociedade.

\section{BIBLIOGRAFIA}

ASHLEY, P. et al. Etica e responsabilidade social nos negócios. São Paulo: Saraiva, 2002.

COHEN, Allan R.; FINK, Stephen L. Comportamento organizacional - conceitos e estudos de casos. 7aa ed. Rio de Janeiro: Campus, 2003.

COSTA, Benny K. e ALMEIDA, Martinho I. R. Estratégia: perspectivas e aplicações. São Paulo: Atlas, 2002. 
FERRELL, O.C. et al. Etica empresarial. Rio de Janeiro: Reichmann e Afonso Editores, 2001.

GIL, Antônio Carlos. Métodos e técnicas de pesquisa social. São Paulo: Atlas, 1999.

GODOY, A. S. Introdução à pesquisa qualitativa e suas possibilidades. Revista de Administração de Empresas, V. 35, oㅡ 2, p57-63. Mar/Abr. 1995.

HUDSON, Mike. Administrando organizações do terceiro setor: o desafio de administrar sem receita. São Paulo: Makron Books, 1999.

KISIL, Marcos. Organização Social e Desenvolvimento Sustentável: projetos de base comunitária. Artigo, 2000.

LEVITT, Theodore.Third Sector- nem tacties for a responsive society. Harvard University, EUA: 1973.

MELO NETO, Francisco P. e FROES, César. Gestão da responsabilidade social corporativa: o caso brasileiro. Rio de Janeiro: Qualitymark Ed., 2001.

MOSCOVICl, Fela. Equipes dão certo: a multiplicação do talento humano. $5^{\mathrm{a}} \mathrm{Ed}$. Rio de Janeiro: José Olympio, 1999.

OLIVEIRA, Djalma P. R. Planejamento estratégico: conceitos, metodologia, práticas. 13 Ed. São Paulo: Atlas, 1999.

SALAMON, Lester. Estratégias para o fortalecimento do Terceiro Setor. Conferencia proferida durante o III Encontro Ibero-Americano para o Terceiro Setor, Rio de Janeiro, 1996.

THILOLLENT, Michel. Metodologia da pesquisa-ação. São Paulo: Cortez Ed., 1985.

VASCONCELLOS FILHO, Paulo de, PAGNONCELLI, Dernizo. Construindo estratégias para vencer. Rio de Janeiro: Campus, 2001. 